\title{
Remarkable promotion effect of trace sulfation on OMS-2 nanorod catalysts for the catalytic combustion of ethanol
}

\author{
Jie Zhang, Changbin Zhang*, Hong He* \\ Research Center for Eco-Environmental Sciences, Chinese Academy of Sciences, Beijing 100085, China. E-mail: faty_yan@163.com
}

\section{A R T I C L E I N F O}

Article history:

Received 15 November 2014

Revised 6 February 2015

Accepted 9 February 2015

Available online 15 June 2015

Keywords:

Manganese oxide

Octahedral molecular sieves (OMS-2)

Catalytic oxidation

VOCs

Lattice oxygen

\begin{abstract}
A B S T R A C T
OMS-2 nanorod catalysts were synthesized by a hydrothermal redox reaction method using $\mathrm{MnSO}_{4}\left(\mathrm{OMS}-2-\mathrm{SO}_{4}\right)$ and $\mathrm{Mn}\left(\mathrm{CH}_{3} \mathrm{COO}\right)_{2}(\mathrm{OMS}-2-\mathrm{AC})$ as precursors. $\mathrm{SO}_{4}^{2-}$-doped OMS-2-AC catalysts with different $\mathrm{SO}_{4}^{2-}$ concentrations were prepared next by adding $\left(\mathrm{NH}_{4}\right)_{2} \mathrm{SO}_{4}$ solution into OMS-2-AC samples to investigate the effect of the anion $\mathrm{SO}_{4}^{2-}$ on the OMS-2-AC catalyst. All catalysts were then tested for the catalytic oxidation of ethanol. The $\mathrm{OMS}-2-\mathrm{SO}_{4}$ catalyst synthesized demonstrated much better activity than OMS-2-AC. The $\mathrm{SO}_{4}^{2-}$ doping greatly influenced the activity of the OMS-2-AC catalyst, with a dramatic promotion of activity for suitable concentration of $\mathrm{SO}_{4}^{2-}\left(\mathrm{SO}_{4} /\right.$ catalyst $\left.=0.5 \% \mathrm{~W} / \mathrm{W}\right)$. The samples were characterized by X-ray diffraction (XRD), field emission scanning electron microscopy (FE-SEM), transmission electron microscopy (TEM), X-ray photoelectron spectroscopy (XPS), inductively coupled plasma optical emission spectroscopy (ICP-OES), $\mathrm{NH}_{3}$-TPD and $\mathrm{H}_{2}$-TPR techniques. The results showed that the presence of a suitable amount of $\mathrm{SO}_{4}^{2-}$ species in the OMS-2-AC catalyst could decrease the Mn-O bond strength and also enhance the lattice oxygen and acid site concentrations, which then effectively promoted the catalytic activity of OMS-2-AC toward ethanol oxidation. Thus it was confirmed that the better catalytic performance of OMS-2-SO ${ }_{4}$ compared to OMS-2-AC is due to the presence of some residual $\mathrm{SO}_{4}^{2-}$ species in OMS-2- $\mathrm{SO}_{4}$ samples.
\end{abstract}

(c) 2015 The Research Center for Eco-Environmental Sciences, Chinese Academy of Sciences. Published by Elsevier B.V.

\section{Introduction}

Volatile organic compounds (VOCs) are major organic pollutants in the atmosphere and are very harmful to human health (Jacobson, 2007). Industrial pollution and vehicle emissions are the main sources of VOCs. Ethanol is a widely used solvent and an important fuel supplement for vehicles, and has been recognized as one of the major contributors to VOC pollution (Poulopoulos et al., 2001). Therefore, it is of great importance to develop an effective method for ethanol elimination. Catalytic oxidation is considered to be the most effective technology for this purpose, because VOCs can be oxidized to $\mathrm{CO}_{2}$ over certain catalysts at much lower temperatures than in thermal oxidation. There are two main types of conventional catalysts used for ethanol oxidation reactions: noble metals (Avgouropoulos et al., 2006; Mitsui et al., 2008; Tang et al., 2005) and metal oxides (Idriss and Seebauer, 2000; Li et al., 2011; Ye et al., 2006; Trawczyñski et al., 2005; Luo et al., 2000). Taking account of economic factors and catalytic properties, recent studies on catalytic oxidation of ethanol have been more focused on metal oxide-based catalysts.

Manganese oxides, especially OMS (octahedral molecular sieve) oxides, have many intrinsic advantages as oxidation catalysts, since OMS oxides have a variety of 3D structures (such as OL-1, OMS-1, OMS-2, etc.), and Mn atoms are present in various oxidation states $\left(\mathrm{Mn}^{4+}, \mathrm{Mn}^{3+}, \mathrm{Mn}^{2+}\right)$ in these

\footnotetext{
* Corresponding authors. E-mail: cbzhang@rcees.ac.cn (Changbin Zhang), honghe@rcees.ac.cn (Hong He).
} 
structures (Suib, 2008; Wang et al., 2012). The OMS-2 structure comprises a peculiar sharing of $2 \times 2\left[\mathrm{MnO}_{6}\right]$ octahedral chains that form one-dimensional tunnel structure with a pore size of $0.46 \mathrm{~nm} \times 0.46 \mathrm{~nm}$. OMS- 2 catalysts have been found to be particularly effective in ethyl acetate (Gandhe et al., 2007), benzyl alcohol (Makwana et al., 2002) and benzene (Luo et al., 2000) oxidation compared with other OMS materials. A great deal of research has been carried out to improve the catalytic activity of OMS-2 by various means, such as using different preparation methods (Malinger et al., 2006), incorporation of metal cations into the OMS-2 tunnel (Chen et al., 2002) and using different precursors (Wang and $\mathrm{Li}, 2010)$. Alkali metal cations and $\mathrm{NH}_{4}^{+}$cations have been used as the templates to synthesize $2 \times 2$ tunnel structures (A-OMS-2; $\mathrm{A}=\mathrm{Li}, \mathrm{Na}, \mathrm{K} \mathrm{Rb}$, or $\mathrm{NH}_{4}^{+}$). It was found that the nature of the cations affects the crystallinity, microstructure, and properties of these materials such as the surface area, thermal stability, and chemical composition (Liu et al., 2003). Hou et al. (2014) recently reported that increasing the $\mathrm{K}^{+}$ concentration could greatly enhance the lattice oxygen activity of OMS-2 nanorod catalysts, thus significantly increasing the catalytic activity for benzene oxidation. The precursor of OMS-2 was also found to have a big influence on the activity. Wang and $\mathrm{Li}$ (2010) observed that OMS-2(S), prepared using $\mathrm{MnSO}_{4}$ as precursor, exhibited better catalytic performance in ethanol oxidation than OMS-2(AC), with $\mathrm{Mn}\left(\mathrm{CH}_{3}\right.$ $\mathrm{COO})_{2}$ as precursor, and they attributed this to the weaker $\mathrm{Mn}-\mathrm{O}$ bond in OMS-2(S), resulting in more lattice defects and labile lattice oxygen. However, they did not discuss the factor in OMS-2(S) that induces this weaker Mn-O bond.

It is known that $\mathrm{SO}_{4}^{2-}$ treatment of catalysts can change the catalytic behavior significantly in some cases. It has been reported that the addition of $\mathrm{SO}_{4}^{2-}$ enhanced the activity of $\mathrm{MoOx}$ and $\mathrm{VOx} / \mathrm{TiO}_{2}$ for the reduction of $\mathrm{NO}$ with $\mathrm{NH}_{3}$ or $\mathrm{H}_{2}$. Wang et al. (2011) recently also found that the sulfation of $\mathrm{Zr}-$ Co hydroxides induced higher activity in $\mathrm{Pd} / \mathrm{ZC}$ catalysts for $\mathrm{CH}_{4}$-SCR of NOx. The positive effect of $\mathrm{SO}_{4}^{2-}$ on the activity was mainly ascribed to the change in acidity on the catalyst surface. It is also well known that the acidic properties of mixed oxide catalysts play an important role in the catalytic oxidation of hydrocarbons, and strong acidity could generally facilitate the breaking of carbon-carbon bonds and promote $\mathrm{CO}_{2}$ production (Rajesh and Ozkan, 1993). Therefore, we proposed that the anion $\mathrm{SO}_{4}^{2-}$ may also have a great influence on OMS-2 activity, and that the better performance of OMS-2(S) for ethanol oxidation compared to OMS-2(AC) is possibly related to the presence of $\mathrm{SO}_{4}^{2-}$ species.

Herein, OMS-2 catalysts were first synthesized by a hydrothermal method using $\mathrm{MnSO}_{4}$ and $\mathrm{Mn}\left(\mathrm{CH}_{3} \mathrm{COO}\right)_{2}$ as the precursors. The OMS- $\mathrm{SO}_{4}$ catalyst $\left(\mathrm{MnSO}_{4}\right.$ precursor) exhibited better catalytic performance than the OMS-2-AC catalyst $\left(\mathrm{Mn}\left(\mathrm{CH}_{3} \mathrm{COO}\right)_{2}\right.$ precursor). We next prepared $\mathrm{SO}_{4}^{2-}$-doped OMS-2-AC catalysts with different $\mathrm{SO}_{4}^{2-}$ concentrations to investigate the effect of the anion $\mathrm{SO}_{4}^{2-}$ on the OMS-2-AC catalyst for ethanol oxidation. It was demonstrated that a suitable $\mathrm{SO}_{4}^{2-}$ concentration could dramatically promote the activity of the OMS-2-AC catalyst. In addition, the samples were characterized by several methods, and the mechanism of the promoting effect of sulfation on the OMS-2 catalyst was also elucidated. Based on the obtained results, we confirmed that the better catalytic performance of OMS-2- $\mathrm{SO}_{4}$ compared to OMS-2-AC is due to the presence of some residual $\mathrm{SO}_{4}^{2-}$ species in the OMS-2- $\mathrm{SO}_{4}$ sample.

\section{Experimental}

\subsection{Catalyst preparation}

OMS-2 catalysts were prepared by a hydrothermal method that mainly depends on self-redox between $\mathrm{Mn}^{7+}\left(\mathrm{KMnO}_{4}\right)$ and $\mathrm{Mn}^{2+}$ $\left(2 \mathrm{MnO}_{4}^{-}(\mathrm{aq})+3 \mathrm{Mn}^{2+}(\mathrm{aq}) \rightarrow 5 \mathrm{MnO}_{x}(\mathrm{~s})\right) \cdot \mathrm{Mn}\left(\mathrm{CH}_{3} \mathrm{COO}\right)_{2}$ and $\mathrm{MnSO}_{4}$ were used as precursors to provide the $\mathrm{Mn}^{2+}$ source. The $\mathrm{KMnO}_{4}$ solution was added into a $\mathrm{Mn}^{2+}$ solution $\left(\mathrm{Mn}\left(\mathrm{CH}_{3} \mathrm{COO}\right)_{2}\right.$ or $\mathrm{MnSO}_{4}$ ) at a $\mathrm{MnO}_{4}^{-} / \mathrm{Mn}^{2+}$ molar ratio of 0.78 , then $2 \mathrm{~mL}$ nitric acid was added to adjust the $\mathrm{pH}$ value. The mixed solution was stirred for $1 \mathrm{hr}$ and then placed in a Teflon liner and sealed in a stainless-steel vessel, and a hydrothermal treatment was performed at $100^{\circ} \mathrm{C}$ for $24 \mathrm{hr}$. The product was separated by filtration, washed several times with deionized water and dried at $100^{\circ} \mathrm{C}$ overnight. All the samples were calcined at $400^{\circ} \mathrm{C}$ in air for $2 \mathrm{hr}$. The as-prepared catalysts are designated as OMS-2-AC and $\mathrm{OMS}-2-\mathrm{SO}_{4}$, respectively.

In order to assess the influence of sulfation species on activity, $\mathrm{SO}_{4}^{2-}$-doped OMS-2 was next obtained by adding a $\left(\mathrm{NH}_{4}\right)_{2} \mathrm{SO}_{4}$ solution into OMS-2-AC samples. $3.0 \mathrm{~g}$ OMS-2-AC catalyst was mixed with $30 \mathrm{~mL}$ distilled water in a beaker, then $12.4,20.6,41.2$, or $82.4 \mathrm{mg}$ of $\left(\mathrm{NH}_{4}\right)_{2} \mathrm{SO}_{4}$ was added into the solution under vigorous magnetic stirring for $1 \mathrm{hr}$, and dried at $100^{\circ} \mathrm{C}$ overnight. All the samples were calcined at $400^{\circ} \mathrm{C}$ in air for $2 \mathrm{hr}$. The results of inductively coupled plasma-optical emission spectroscopy (ICP-OES, Optima-2000DV, PerkinElmer Co, Waltham, Massachusetts, USA) measurements (determined by elemental analysis of S) showed that the $\mathrm{SO}_{4}^{2-}$ loading was $0.3,0.5$, 1.0, and $2.0 \mathrm{wt} . \%$, respectively, and the catalysts are hereinafter designated as $0.3 \%, 0.5 \%, 1.0 \%$, and $2.0 \% \mathrm{SO}_{4}$-OMS-AC.

\subsection{Material characterizations}

The samples were characterized structurally by X-ray diffraction (XRD, X'Pert Pro, PANalytical Co, Almelo, Holland), using a Bruker D8 Advance Diffractometer with a monochromatic Cu Ká source operated at $40 \mathrm{kV}$ and $40 \mathrm{~mA}$. The diffraction patterns were taken at room temperature in the range of $10<2 \mathrm{è}<90^{\circ}$. For phase identification purposes, the JCPDS database of reference compounds was used. Surface area and pore volume were measured using a Quadrasorb system (Autosorb-IQ-1MP, Quantachrome Co, Boynton Beach, Florida, USA) at liquid nitrogen temperature $(77 \mathrm{~K})$. Transmission electron microscopy (TEM, JEM-2011LaB6, JEOL Ltd., Tokyo, Japan) images were obtained with a JEOL JEM-2011LaB6 at an accelerating voltage of $200 \mathrm{kV}$. The samples were ultrasonically suspended in ethanol and deposited on a copper grid covered with a thin layer of holey carbon. The field-emission scanning electron microscopy (FE-SEM, S-3000N, Hitachi Ltd., Tokyo, Japan) images were taken using a SU-8020 scanning electron microscope. The samples for FE-SEM measurements were prepared by depositing the powder on graphite tape.

ICP-OES (inductively coupled plasma optical emission spectroscopy, Prodigy XP, Leeman LABS, Hudson, New Hampshire, 
USA) was carried out as follows. $100 \mathrm{mg}$ of sample was dissolved in concentrated hydrochloric acid at $90^{\circ} \mathrm{C}$ for $4 \mathrm{hr}$, at which point no solid remained. The concentrated liquid was diluted to an appropriate concentration and then analyzed by a programmable array detector.

X-ray photoelectron spectroscopy (XPS, PHI Quantera, ULVAC-PHI Inc., Kanagawa, Japan) data were obtained with an electron spectrometer (AXIS Ultra, Kratos Analytical, Inc., Manchester, UK) with $\mathrm{Al}$ Ká radiation at a pressure lower than $10^{-7} \mathrm{~Pa}$. The binding energies were referenced to the $\mathrm{C} 1 \mathrm{~s}$ line at $284.8 \mathrm{eV}$ from adventitious carbon. The spectra were calculated using the XPSPEAK program by curve fitting with a Gaussian/Lorentzian ratio of 90/10 after smoothing and subtraction of the Shirley-type background.

$\mathrm{H}_{2}$ temperature programmed reduction $\left(\mathrm{H}_{2}-\mathrm{TPR}\right)$ and ammonia temperature programmed desorption ( $\left.\mathrm{NH}_{3}-\mathrm{TPD}\right)$ were performed in an apparatus (AutoChem II 2920, MICROMERITICS INSTRUMENT, Norcross, GA, USA) equipped with a computer-controlled CryoCooler and a thermal conductivity detector (TCD). $\mathrm{H}_{2}$-TPR profiles were obtained by passing a flow of $10 \% \mathrm{H}_{2} / \mathrm{Ar}$ at a rate of $50 \mathrm{~mL} / \mathrm{min}$ (STP) through the sample (weight around $30 \mathrm{mg}$ ). The temperature was increased from 50 to $1000^{\circ} \mathrm{C}$ at a rate of $10^{\circ} \mathrm{C} / \mathrm{min}$, and the $\mathrm{H}_{2}$ consumption was monitored by TCD after removal of produced $\mathrm{H}_{2} \mathrm{O}$. For $\mathrm{NH}_{3}-\mathrm{TPD}$, $100 \mathrm{mg}$ of the samples were first pre-heated in air at $300^{\circ} \mathrm{C}$ for $30 \mathrm{~min}$. After preheating, ammonia adsorption was carried out at $40^{\circ} \mathrm{C}$ for $90 \mathrm{~min}$ by passing a gas mixture of $260 \mathrm{ppm}$ ammonia in Argon over the sample at a flow rate of $50 \mathrm{~mL} /$ min. The sample was then flushed with $60 \mathrm{~mL} / \mathrm{min}$ Argon to remove the surface physisorbed ammonia. After flushing, the sample was heated under a flow of Argon from 50 to $900^{\circ} \mathrm{C}$ with a temperature ramp of $10^{\circ} \mathrm{C} / \mathrm{min}$.

\subsection{Catalytic evaluation}

Activity tests for the catalytic oxidation of ethanol over the catalysts $(\sim 50 \mathrm{mg})$ were performed in a fixed-bed quartz flow reactor with a gas mixture containing $800 \mathrm{ppm}$ ethanol, $20 \%$ $\mathrm{O}_{2}$ and $\mathrm{N}_{2}$ balance at a total flow rate of $100 \mathrm{~mL} / \mathrm{min}$ (gas hourly space velocity (GHSV) $=36,000 \mathrm{hr}^{-1}$ ). The reactants and the reaction products of a possible incomplete reaction were analyzed by using an on-line gas chromatograph (GC-6890N, Agilent Technologies, Santa Clara, CA, USA) equipped with a Porapak $\mathrm{Q}$ column for the analysis of ethanol, $\mathrm{CO}_{2}$, and acetaldehyde, and quantified by using a TCD. The temperatures were measured with a thermocouple, and the data reported at each reaction temperature were the average of at least two steady-state measurements.

\section{Results}

\subsection{Catalytic activity}

The as-prepared OMS-2-SO $\mathrm{O}_{4}$ and OMS-2-AC catalysts were evaluated for the oxidation of ethanol. Fig. $1 a$ and $b$ exhibits the ethanol conversion and the acetaldehyde yield over the catalysts as a function of reaction temperature, with an inlet ethanol concentration of $800 \mathrm{ppm}$ and a GHSV of 36,000 $\mathrm{hr}^{-1}$, respectively. As shown in Fig. $1 \mathrm{a}$, the $\mathrm{OMS}-2-\mathrm{SO}_{4}$ catalyst
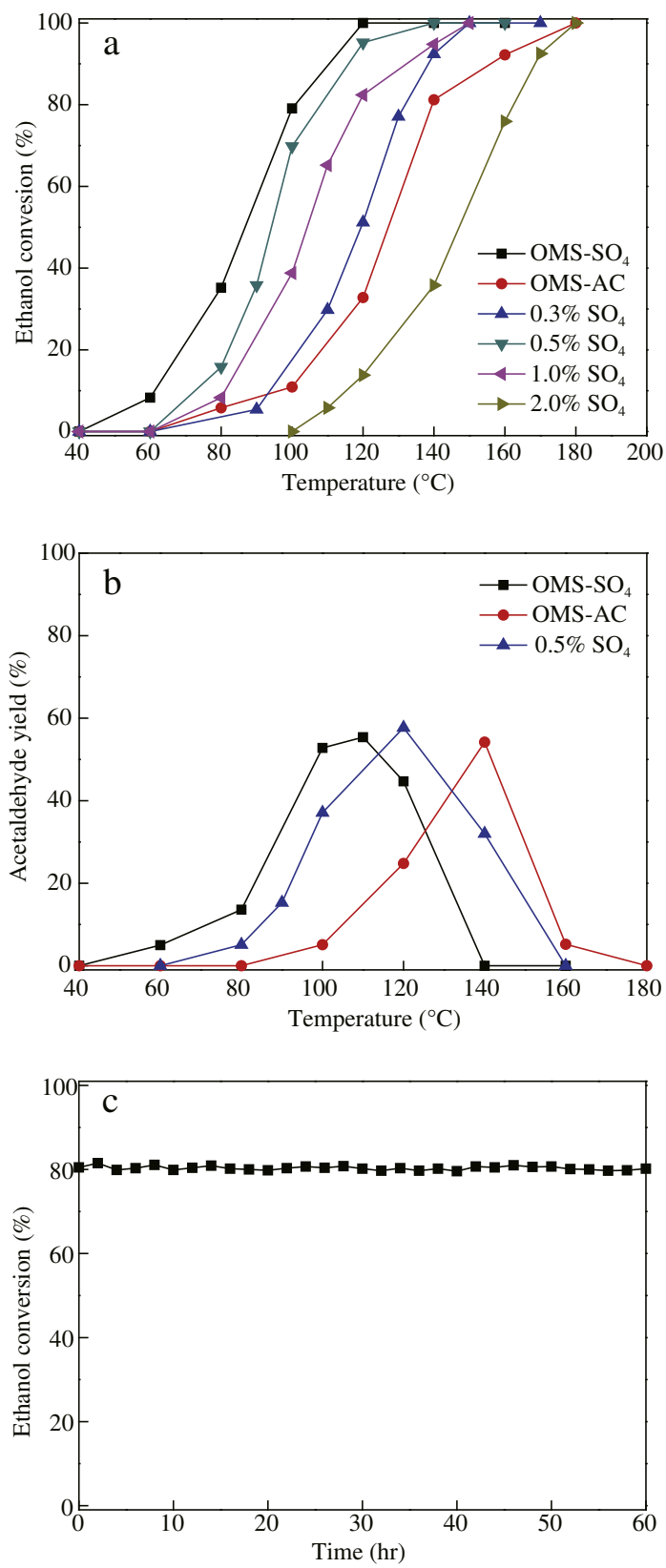

Fig. 1 - (a) Ethanol conversion performance of different catalysts; (b) acetaldehyde yield of $\mathrm{OMS}-2-\mathrm{SO}_{4}, 0.5 \%$ $\mathrm{SO}_{4}$-OMS-AC and OMS-2-AC catalysis during ethanol oxidation; (c) ethanol conversion on $0.5 \% \mathrm{SO}_{4}$-OMS-AC with time on stream at $110^{\circ} \mathrm{C}$. Reaction conditions: $800 \mathrm{ppm}$ ethanol, $20 \mathrm{vol} . \% \mathrm{O}_{2}$, and $\mathrm{N}_{2}$ as balance gas; gas hourly space velocity $36,000 \mathrm{hr}^{-1}$. Different catalysts refer to Section 1.1.

showed much better performance than the OMS-2-AC catalysts. $100 \%$ ethanol conversion was achieved at $120^{\circ} \mathrm{C}$ over OMS-2- $\mathrm{SO}_{4}$ and at $180^{\circ} \mathrm{C}$ over the OMS-2-AC catalyst, respectively. As shown in Fig. 1b, acetaldehyde is the major by-product during the ethanol oxidation process, and $100 \%$ $\mathrm{CO}_{2}$ yield was obtained at $140^{\circ} \mathrm{C}$ over OMS-2-SO $\mathrm{S}_{4}$, while it was still not fully achieved at $180^{\circ} \mathrm{C}$ over the OMS-2-AC catalyst. Compared with previously reported OMS-2 catalysts, the as-prepared $\mathrm{OMS}-2-\mathrm{SO}_{4}$ catalyst is more active than $\mathrm{MnOx}$ 
catalysts synthesized by an exotemplating method (Bastos et al., 2009) and other OMS-2 material prepared by a refluxing method (Wang and $\mathrm{Li}, 2010$ ), and is even superior to $\mathrm{Pt} / \mathrm{Al}_{2} \mathrm{O}_{3}$ catalysts (Avgouropoulos et al., 2006).

The $\mathrm{SO}_{4}^{2-}$-doped OMS-2-AC materials were tested next, and the results are also shown in Fig. 1 a. When the $\mathrm{SO}_{4}^{2-}$ amount was increased from $0.3 \%$ to $0.5 \%$, the catalytic activity of OMS-2-AC was clearly enhanced, and the profile of ethanol conversion shifted to a lower temperature range. However, further increasing the $\mathrm{SO}_{4}^{2-}$ amount to $1.0 \%$ and $2.0 \%$ resulted in a sharp drop in ethanol conversion. It is clear that the $0.5 \%$ $\mathrm{SO}_{4}$-OMS-AC showed the best performance, which is almost equal to that of the OMS-2- $\mathrm{SO}_{4}$ sample. The above results indicated that a suitable amount of $\mathrm{SO}_{4}^{2-}$ modification could significantly promote the activity of the OMS-2-AC material; however, too much $\mathrm{SO}_{4}^{2-}$ species would act as a poison to the catalyst. In addition, these results also demonstrated that the much higher activity of the OMS-2-SO ${ }_{4}$ sample compared to OMS-2-AC is possibly due to the presence of $\mathrm{SO}_{4}^{2-}$ in this sample. The catalytic performance of the $0.5 \% \mathrm{SO}_{4}$-OMS-AC catalyst was also checked by long isothermal tests. As shown in Fig. 1c, approximately $80 \%$ ethanol conversion was maintained over a $60 \mathrm{hr}$-long test, demonstrating the excellent stability of this catalyst.

\section{2. $\mathrm{XRD}$ and BET tests}

Fig. 2 shows the XRD patterns of OMS-2-SO 4 , OMS-2-AC and $\mathrm{SO}_{4}^{2-}$-modified OMS-2-AC samples. The (101), (002), (301), (211), (310), (114) and (600) reflections at 2è = 12.7, 18.0, 28.7, 37.5, $41.8,50.0$ and $56.2^{\circ}$ were observed, revealing that all the as-synthesized samples can be indexed to the pure tetragonal cryptomelane structure of OMS-2 $\left(\mathrm{KMn}_{8} \mathrm{O}_{16}, \mathrm{JCPDS} 34-168\right)$. In addition, when the $\mathrm{SO}_{4}^{2-}$ amount was $0.3 \%$ and $0.5 \%$, no $\mathrm{SO}_{4}^{2-}$-related XRD peaks were observed, showing that $\mathrm{SO}_{4}^{2-}$ species are highly dispersed on the catalyst or incorporated into the lattice of OMS-2-AC samples. However, when the $\mathrm{SO}_{4}^{2-}$ amount was $1.0 \%$ and $2.0 \%$, excessive $\mathrm{SO}_{4}^{2-}$ resulted in the appearance of a weak $\mathrm{MnSO}_{4}$ peak (JCPDS 3-810) at $32.8^{\circ}$.

The BET surface area and pore parameters are presented in Table 1. The $\mathrm{OMS}-\mathrm{SO}_{4}$ catalyst showed a slightly higher

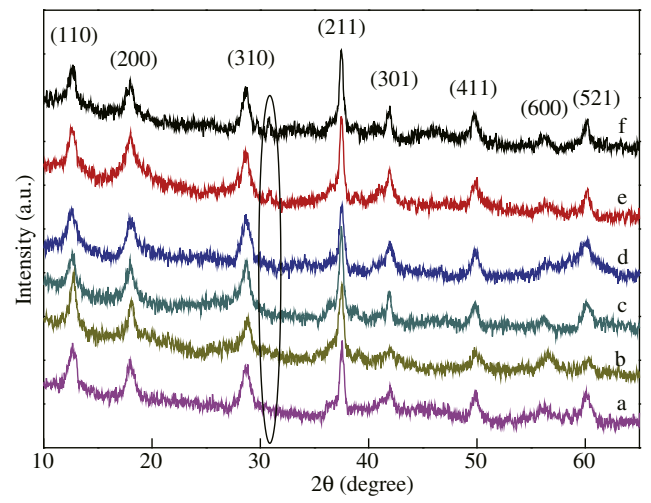

Fig. 2 - XRD (X-ray diffraction) patterns of synthesized OMS-2 catalysts. (line a) OMS-2-SO c) $0.3 \% \mathrm{SO}_{4}$-OMS-AC, (line d) $0.5 \% \mathrm{SO}_{4}$-OMS-AC, (line e) $1.0 \%$ $\mathrm{SO}_{4}$-OMS-AC and (line f) $2.0 \% \mathrm{SO}_{4}$-OMS-AC.
Table 1-BET and ICP information for OMS-2-SO $\mathrm{S}_{4}$ and OMS-2-AC catalysts.

\begin{tabular}{lcccc}
\multicolumn{1}{c}{ Sample } & $\begin{array}{c}\text { BET } \\
\text { surface } \\
\text { area }\left(\mathrm{m}^{2} / \mathrm{g}\right)\end{array}$ & $\begin{array}{c}\text { Pore } \\
\text { volume } \\
\left(\mathrm{cm}^{3} / \mathrm{g}\right)\end{array}$ & $\begin{array}{c}\text { Pore } \\
\text { diameter } \\
(\mathrm{nm})\end{array}$ & $\begin{array}{c}\mathrm{SO}_{4}^{2-} \text { / } \\
\text { catalyst } \\
(\%, \mathrm{~W} / \mathrm{W})\end{array}$ \\
\hline $\begin{array}{l}\text { OMS-2-SO } \\
\text { 0.5\% }\end{array}$ & 114.1 & 0.51 & 30.4 & 0.5 \\
$\begin{array}{l}\mathrm{SO}_{4} \text {-OMS-AC } \\
\text { OMS-2-AC }\end{array}$ & 96.2 & 0.48 & 30.2 & 0.5 \\
\hline
\end{tabular}

OMS-2-SO ${ }_{4}, \mathrm{SO}_{4}$-OMS-AC and OMS-2-AC refer to Section 1.1.

surface area and pore volume, and similar $\mathrm{BJH}$ pore diameter compared to the OMS-2-AC catalyst. The $0.5 \mathrm{wt} \% \mathrm{SO}_{4}^{2-}$ addition to OMS-2-AC did not induce any obvious change to the above-mentioned parameters. The contents of $\mathrm{SO}_{4}^{2-}$ in OMS-2-SO ${ }_{4}, \mathrm{OMS}-2-\mathrm{AC}$ and $\mathrm{SO}_{4}^{2-}$-modified OMS-2-AC samples were measured by ICP-OES, and the results are also presented in Table 1. When using $\mathrm{MnSO}_{4}$ as precursor, about 0.5 wt.\% residual sulfation species remained on $\mathrm{OMS}-2-\mathrm{SO}_{4}$ samples. No $\mathrm{SO}_{4}^{2-}$ species were detected when using $\mathrm{MnAC}$ as precursor. After doping $20.6 \mathrm{mg}\left(\mathrm{NH}_{4}\right)_{2} \mathrm{SO}_{4}$ into $3 \mathrm{~g}$ OMS-2-AC samples, about 0.5 wt.\% $\mathrm{SO}_{4}^{2-}$ species was found to be loaded, showing minimal loss of $\mathrm{SO}_{4}^{2-}$ species during the preparation.

\subsection{XPS results}

The chemical states of $\mathrm{OMS}-2-\mathrm{SO}_{4}, \mathrm{OMS}-2-\mathrm{AC}$ and $0.5 \%$ $\mathrm{SO}_{4}$-OMS-AC catalysts were determined by XPS and the results are presented in Table 2 . Only $\mathrm{Mn}^{4+}$ species were detected, at binding energies around $642.4 \mathrm{eV}\left(\mathrm{Mn} \mathrm{2} \mathrm{p}_{3 / 2}\right)$ and $654.1 \mathrm{eV}\left(\mathrm{Mn} \mathrm{2} \mathrm{p}_{1 / 2}\right)$. No XPS peaks of other Mn species were observed. This suggests that manganese species were present predominantly as $\mathrm{MnO}_{2}$ in all the samples (Liang et al., 2008). In addition, the results above indicated that the use of different precursors and the $0.5 \% \mathrm{SO}_{4}^{2-}$ doping did not change the binding energy of $\mathrm{Mn} 2 \mathrm{p}$.

The $O$ 1s spectra for all the samples presented two peaks $\left(\mathrm{O}_{\alpha}\right.$ and $\left.\mathrm{O}_{\beta}\right)$ with $\mathrm{BE}$ values at 529.8 and $532.2 \mathrm{eV}$. The peak at $532.2 \mathrm{eV}$ may be assigned to less electron-rich surface oxygen species $\left(\mathrm{O}_{\alpha}\right)$, and another peak at $529.8 \mathrm{eV}$ was ascribed to the lattice oxygen species $\mathrm{O}_{2}^{-}\left(\mathrm{O}_{\beta}\right)$ (Wang and $\mathrm{Li}, 2010$ ). The $\mathrm{O}_{\beta}$ concentrations were calculated and are summarized in Table 2. It is shown that the OMS-SO $\mathrm{O}_{4}$ catalyst contained $72 \%$ $\mathrm{O}_{\beta}$ species, which is higher than that in the OMS-2-AC catalyst (64\%). Interestingly, doping $0.5 \% \mathrm{SO}_{4}^{2-}$ species into OMS-2-AC samples clearly increased the $\mathrm{O}_{\beta}$ concentrations from $64 \%$ to $68 \%$, indicating that the higher $\mathrm{O}_{\beta}$ concentration in the

\begin{tabular}{|c|c|c|c|c|c|}
\hline \multirow[t]{2}{*}{ Sample } & \multirow{2}{*}{$\begin{array}{c}\mathrm{Mn} 2 \mathrm{p}_{3 / 2} \\
(\mathrm{eV})\end{array}$} & \multirow{2}{*}{$\begin{array}{c}\text { Mn 2p } p_{1 / 2} \\
(e V)\end{array}$} & \multicolumn{2}{|c|}{ O 1s (eV) } & \multirow{2}{*}{$\begin{array}{c}\mathrm{O}_{\beta} / \\
\left(\mathrm{O}_{\alpha}+\mathrm{O}_{\beta}\right)\end{array}$} \\
\hline & & & $\mathrm{O}_{\beta}$ & $\mathrm{O}_{\alpha}$ & \\
\hline OMS-2-SO & 642.4 & 654.1 & 529.8 & 531.1 & 0.72 \\
\hline $0.5 \%$ & 642.3 & 654.0 & 529.8 & 531.1 & 0.68 \\
\hline \multicolumn{6}{|l|}{$\mathrm{SO}_{4}-\mathrm{OMS}-\mathrm{AC}$} \\
\hline OMS-2-AC & 642.2 & 654.0 & 529.8 & 531.1 & 0.64 \\
\hline
\end{tabular}

$\mathrm{O}_{\alpha}$ : the surface oxygen species; $\mathrm{O}_{\beta}$ : the lattice oxygen species $\mathrm{O}_{2}^{-}$. 
OMS-2- $\mathrm{SO}_{4}$ catalyst is possibly due to the presence of some residual $\mathrm{SO}_{4}^{2-}$ species.

\subsection{SEM and TEM results}

The morphologies of OMS-2-SO $\mathrm{SO}_{4}$ OMS-2-AC and $0.5 \%$ $\mathrm{SO}_{4}$-OMS-AC samples were investigated by FE-SEM and HR-TEM, and the samples images are shown in Fig. 3. The FE-SEM results revealed that all of the samples are characterized by a nanorod morphology. High-resolution TEM (HRTEM) images indicated that all of the OMS-2 samples exhibited a single crystal structure with an exposed $\{200\}$ facet (Yuan et al., 2005). These results showed that the use of different precursors and the $0.5 \% \mathrm{SO}_{4}^{2-}$ doping had no influence on the morphology of the OMS-2 catalysts.

\section{5. $\mathrm{NH}_{3}-\mathrm{TPD}$ results}

The surface acidity of mixed oxide catalysts is known to play an important role in the catalytic oxidation of hydrocarbons, and the presence of strong acidity could generally facilitate the breaking of carbon-carbon bonds and promote $\mathrm{CO}_{2}$ production (Rajesh and Ozkan, 1993). Therefore, the surface acidity of OMS-2-SO ${ }_{4}$, OMS-2-AC and 0.5\% $\mathrm{SO}_{4}$-OMS-AC samples was next measured by the $\mathrm{NH}_{3}$-TPD method, and the results are shown in Fig. 4 and Table 3. As shown in Fig. 4, the three samples have obvious $\mathrm{NH}_{3}$ desorption in the temperature range of $75-300^{\circ} \mathrm{C}$. The OMS-2-AC and 0.5\% $\mathrm{SO}_{4}$-OMS-AC samples had a single kind of acid site, with the maximum of the desorption peak occurring at around $120^{\circ} \mathrm{C}$. In contrast, the $\mathrm{OMS}-2-\mathrm{SO}_{4}$ sample also presented a strong acid site at around $120^{\circ} \mathrm{C}$, but had an additional small shoulder peak at around $250^{\circ} \mathrm{C}$, indicating that the $\mathrm{OMS}-2-\mathrm{SO}_{4}$ catalyst had an additional stronger kind of acid site compared with the OMS-2-AC catalyst. The concentrations of acid sites based on the $\mathrm{NH}_{3}$-TPD results are presented in Table 3. It is shown that the OMS-2-SO $\mathrm{S}_{4}$ catalyst contained $79.9 \mu \mathrm{mol} / \mathrm{g}$ acid sites, much more than the OMS-2-AC catalyst (65.5 imol/g). Clearly, doping $0.5 \% \mathrm{SO}_{4}^{2-}$ species into OMS-2-AC samples enhanced the acid sites from 65.5 to $81.9 \mathrm{imol} / \mathrm{g}$, indicating that the presence of residual $\mathrm{SO}_{4}^{2-}$ species is responsible for the higher concentration of acid sites on OMS-2-SO $\mathrm{SO}_{4}$ than on the OMS-2-AC catalyst, therefore benefiting the catalytic oxidation of ethanol.

\section{6. $\mathrm{H}_{2}$-TPR results}

The redox characteristics of catalysts were next studied by means of TPR experiments. Fig. 5 illustrates the $\mathrm{H}_{2}$-TPR

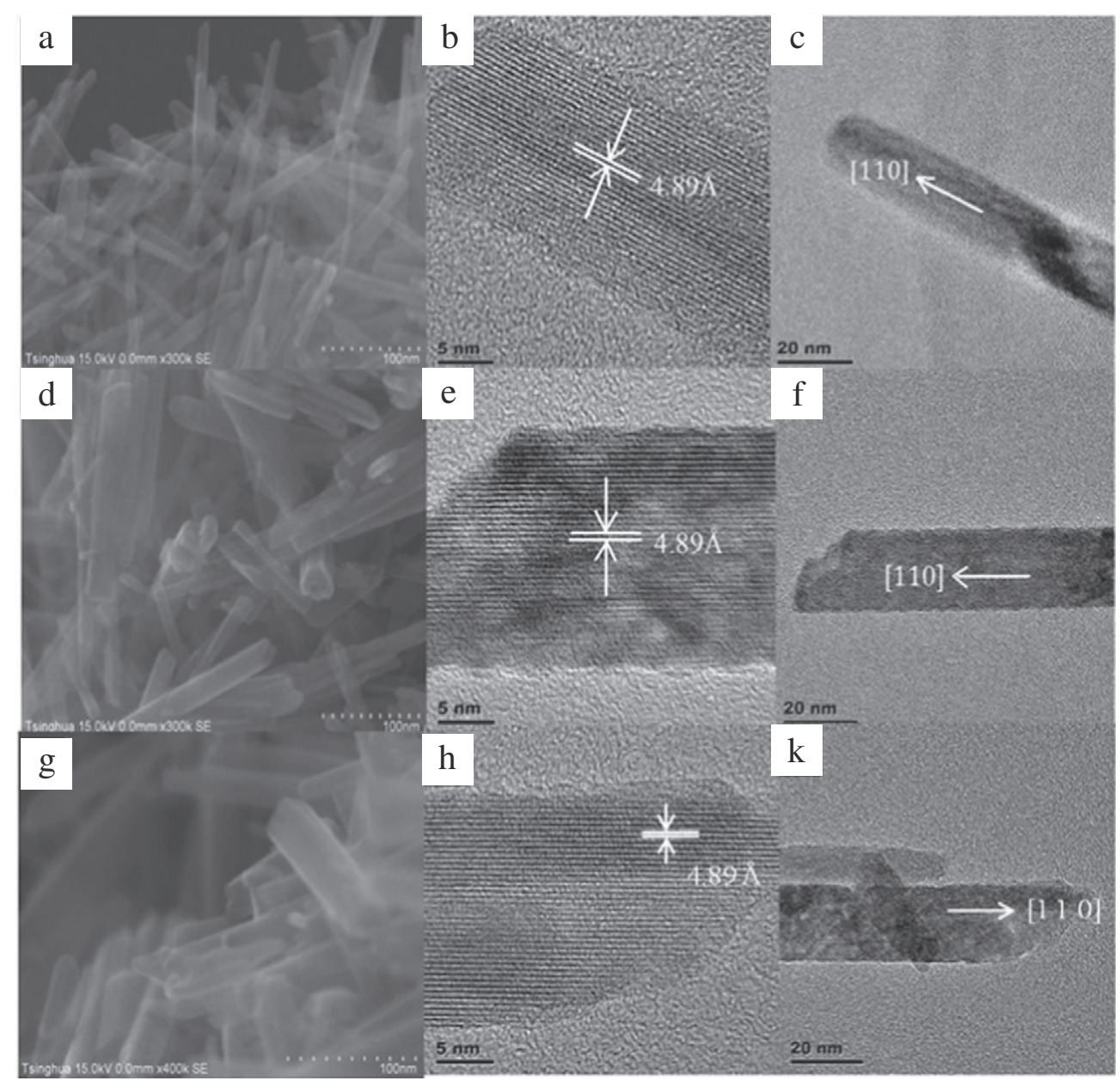

Fig. 3 - FE-SEM (field emission scanning electron microscopy) and HR-TEM (high-resolution transmission electron microscopy) images of as-synthesized OMS-2-AC (a-c), OMS-2- $\mathrm{SO}_{4}(\mathrm{~d}-\mathrm{f})$ and $0.5 \% \mathrm{SO}_{4}-\mathrm{OMS}-\mathrm{AC}(\mathrm{g}-\mathrm{k})$. 


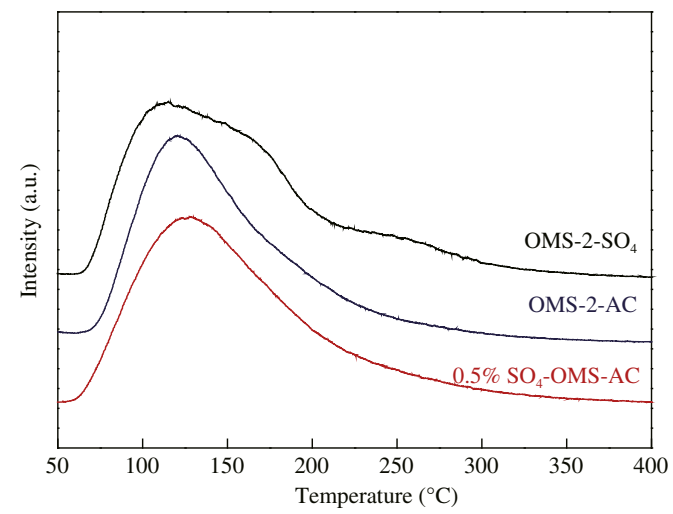

Fig. $4-\mathrm{NH}_{3}$-TPD profiles of OMS-2-SO $\mathrm{O}_{4}$, OMS-2-AC and $0.5 \%$ $\mathrm{SO}_{4}$-OMS-AC catalysts.

profiles of the as-prepared OMS-2 nanorod samples. All catalysts presented a sharp reduction peak with an overlapping shoulder peak in the temperature range from 200 to $330^{\circ} \mathrm{C}$. It is well accepted that the reduction sequence of $\mathrm{MnO}_{2}$ oxidation follows the sequence $\mathrm{MnO}_{2} \rightarrow \mathrm{Mn}_{3} \mathrm{O}_{4} \rightarrow \mathrm{MnO}$ (Tang et al., 2006). Therefore, the first sharp peaks at around 270 to $285^{\circ} \mathrm{C}$ were attributed to $\mathrm{MnO}_{2} \rightarrow \mathrm{Mn}_{3} \mathrm{O}_{4}$; the second shoulder peaks at around $290^{\circ} \mathrm{C}$ were due to $\mathrm{Mn}_{3} \mathrm{O}_{4} \rightarrow \mathrm{Mn}^{2+}$. For OMS-2-SO $\mathrm{SO}_{4}$ OMS-2-AC and $0.5 \% \mathrm{SO}_{4}$-OMS-AC catalysts the sharp peak appears at 270,275 and $282^{\circ} \mathrm{C}$, respectively. The hydrogen consumption was estimated from the calibration of the TCD response by means of the injection of known amounts of nitrogen into the reducing gaseous mixture $\left(\mathrm{H}_{2} /\right.$ $\mathrm{Ar}$ ), and the results are shown in Table 3 . The $\mathrm{H}_{2}$ consumption of OMS-2-SO ${ }_{4}$, OMS-2-AC and 0.5\% SO 4 -OMS-AC was 10.66 , 10.01 and $10.58 \mathrm{mmol} / \mathrm{g}$, respectively. These results indicated that OMS-2- $\mathrm{SO}_{4}$ was more easily reducible than OMS-2-AC, and the doping of $0.5 \% \mathrm{SO}_{4}^{2-}$ species into OMS-2-AC samples clearly increased the reducibility and enhanced the mobility of oxygen species.

\subsection{Mn-O bond and lattice oxygen}

The Mn-O bond of OMS-2 catalysts was found to play an important role in determining their catalytic activity in VOC oxidation (Li et al., 2010). Therefore, the Raman spectra of OMS-2-SO ${ }_{4}, \mathrm{OMS}-2-\mathrm{AC}$ and $0.5 \% \mathrm{SO}_{4}$-OMS-AC samples were measured next to investigate the deformation modes of the $\mathrm{Mn}-\mathrm{O}-\mathrm{Mn}$ bond, and the results are shown in Fig. 6. All samples presented two clear bands at 586 and $647 \mathrm{~cm}^{-1}$, which correspond to the stretching modes of the $\mathrm{Mn}-\mathrm{O}$ lattice

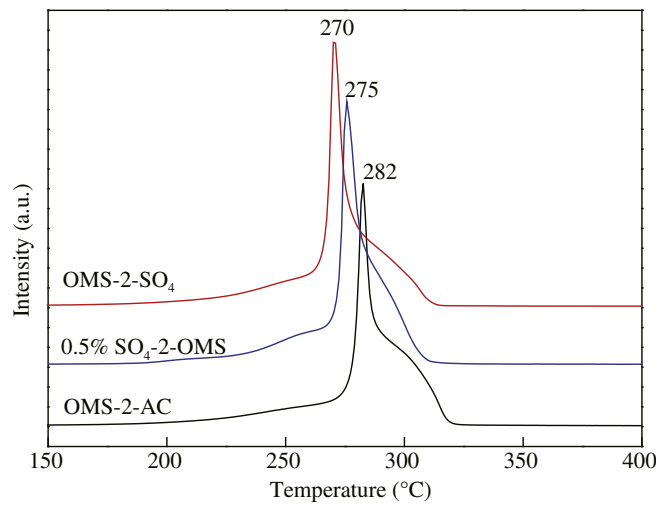

Fig. $5-\mathrm{H}_{2}$-TPR profiles of OMS-2-SO $\mathrm{O}_{4}, 0.5 \% \mathrm{SO}_{4}$-OMS-AC and OMS-2-AC catalysts.

(Wang and $\mathrm{Li}, 2010$ ). The peak widths and intensities of OMS-2-SO $\mathrm{S}_{4}$ were much greater than those of OMS-2-AC, indicating that the $\mathrm{Mn}-\mathrm{O}$ lattice bond in $\mathrm{OMS}-2-\mathrm{SO}_{4}$ was in a more highly distorted state, with more crystal defects in the catalyst, than that in the OMS-2-AC sample. The doping of $0.5 \% \mathrm{SO}_{4}^{2-}$ species into OMS-2-AC samples clearly increased the peak widths and intensities of OMS-2-AC, demonstrating that the presence of $\mathrm{SO}_{4}^{2-}$ species is responsible for the more highly distorted state of $\mathrm{Mn}-\mathrm{O}$ in the $\mathrm{OMS}-2-\mathrm{SO}_{4}$ catalyst. It was reported that sulfation could induce the crystalline transformation of $\mathrm{ZrO}_{2}$ by the interaction of $\mathrm{SO}_{4}^{2-}$ species with $\mathrm{O}$ atoms (Haase and Sauer, 1998). We estimated that $\mathrm{SO}_{4}^{2-}$ species in OMS-2-SO $\mathrm{SO}_{4}$ or $0.5 \% \mathrm{SO}_{4}$-OMS-AC samples had a strong interaction with nearby $\mathrm{Mn}$ atoms, which can affect the $\mathrm{Mn}-\mathrm{O}$ bond strength. This then weakened the Mn-O bond and produced more lattice defects and a more labile lattice, leading to the better activity of OMS-2-SO $\mathrm{SO}_{4}$ in ethanol oxidation.

\section{Conclusions}

In this work, we demonstrated that $\mathrm{SO}_{4}^{2-}$ doping has a great influence on OMS-2-AC catalysts in the catalytic oxidation of ethanol. We found that doping a suitable amount of $\mathrm{SO}_{4}^{2-}$ species into the OMS-2-AC catalyst could decrease the Mn-O bond strength and also enhance the lattice oxygen concentration and number of acid sites, which then effectively promoted the catalytic activity of OMS-2-AC. Thus, it is confirmed that the better catalytic performance of $\mathrm{OMS}-2-\mathrm{SO}_{4}$ compared to OMS-2-AC is closely related to the presence of some residual $\mathrm{SO}_{4}^{2-}$ species in OMS-2-SO ${ }_{4}$ samples.

\section{Table $3-\mathrm{H}_{2}$ and $\mathrm{NH}_{3}$ consumption of OMS-2- $\mathrm{SO}_{4}, 0.5 \% \mathrm{SO}_{4}-\mathrm{OMS}-\mathrm{AC}$ and OMS-2-AC catalysts.}

\begin{tabular}{|c|c|c|c|c|c|c|}
\hline \multirow[t]{2}{*}{ Catalyst } & \multicolumn{2}{|c|}{$\begin{array}{c}\text { Reduction } \\
\text { temperature }(T)\end{array}$} & \multicolumn{3}{|c|}{$\mathrm{H}_{2}$ consumption } & \multirow{2}{*}{$\frac{\mathrm{NH}_{3} \text { consumption }}{\text { Total amount }(\mu \mathrm{mol} / \mathrm{g})}$} \\
\hline & $\mathrm{T}_{\text {low }}\left({ }^{\circ} \mathrm{C}\right)$ & $\mathrm{T}_{\text {high }}\left({ }^{\circ} \mathrm{C}\right)$ & $\mathrm{C}_{\text {low }}(\mathrm{mmol} / \mathrm{g})$ & $\mathrm{C}_{\text {high }}(\mathrm{mmol} / \mathrm{g})$ & $\mathrm{C}_{\text {all }}(\mathrm{mmol} / \mathrm{g})$ & \\
\hline $\mathrm{OMS}-2-\mathrm{SO}_{4}$ & 270 & 290 & 6.87 & 3.79 & 10.66 & 79.9 \\
\hline $0.5 \% \mathrm{SO}_{4}$-OMS-AC & 275 & 290 & 6.78 & 3.80 & 10.58 & 81.9 \\
\hline OMS-2-AC & 282 & 298 & 5.71 & 4.30 & 10.01 & 65.5 \\
\hline
\end{tabular}

$\mathrm{T}_{\text {low }}$ and $\mathrm{T}_{\text {high }}$ are lower and higher temperature at which the peak appears; $\mathrm{C}_{\text {low }}$ and $\mathrm{C}_{\text {high }}$ are the amount of $\mathrm{H}_{2}$ consumption calculated by integrating the peak at lower and higher temperature; $C_{\text {all }}$ is the overall amount of $\mathrm{H}_{2}$ consumption. 


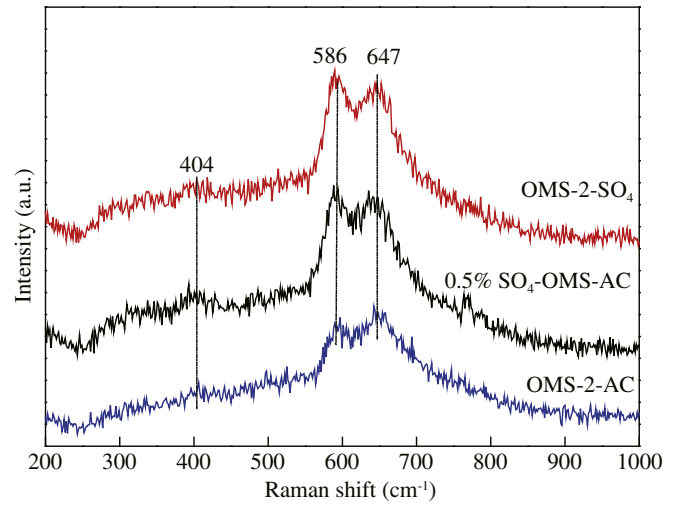

Fig. 6 - Raman spectra of OMS-2-SO $\mathrm{O}_{4}, 0.5 \% \mathrm{SO}_{4}$-OMS-AC and OMS-2-AC catalysts.

\section{Acknowledgments}

This work was financially supported by the National Natural Science Foundation of China (No. 21422706) and the Program of the Ministry of Science and Technology of China (No. 2012AA062702).

\section{R E F E R E N C E S}

Avgouropoulos, G., Oikonomopoulos, E., Kanistras, D., Ioannides, T., 2006. Complete oxidation of ethanol over alkali-promoted $\mathrm{Pt} / \mathrm{Al}_{2} \mathrm{O}_{3}$ catalysts. Appl. Catal. B Environ. 65 (1-2), 62-69.

Bastos, S.S.T., Órfão, J.J.M., Freitas, M.M.A., Pereira, M.F.R., Figueiredo, J.L., 2009. Manganese oxide catalysts synthesized by exotemplating for the total oxidation of ethanol. Appl. Catal. B Environ. 93 (1-2), 30-37.

Chen, X., Shen, Y.F., Suib, S.L., O’Young, C.L., 2002. Characterization of manganese oxide octahedral molecular sieve (M-OMS-2) materials with different metal cation dopants. Chem. Mater. 14 (2), 940-948.

Gandhe, A.R., Rebello, J.S., Figueiredo, J.L., Fernandes, J.B., 2007. Manganese oxide OMS-2 as an effective catalyst for total oxidation of ethyl acetate. Appl. Catal. B Environ. 72 (1-2), 129-135.

Haase, F., Sauer, J., 1998. The surface structure of sulfated zirconia: periodic ab initio study of sulfuric acid adsorbed on $\mathrm{ZrO}_{2}(101)$ and $\mathrm{ZrO}_{2}$ (001). J. Am. Chem. Soc. 120 (51), 13503-13512.

Hou, J.T., Liu, L.L., Li, Y.Z., Mao, M.Y., Lv, H.Q., Zhao, X.J., 2014. Tuning the $\mathrm{K}^{+}$concentration in the tunnel of OMS2nanorodsleadsto a significant enhancement of the catalytic activity for benzene oxidation. Environ. Sci. Technol. 47 (23), 13730-13736.

Idriss, H., Seebauer, E.G., 2000. Reactions of ethanol over metal oxides. J. Mol. Catal. A Chem. 152 (1-2), 201-212.

Jacobson, M.Z., 2007. Effects of ethanol (E85) versus gasoline vehicles on cancer and mortality in the United States. Environ. Sci. Technol. 41 (11), 4150-4157.

Li, H.J., Tana, Zhang, X.J., Huang, X.M., Shen, W.J., 2011. Stability improvement of $\mathrm{ZrO}_{2}$-doped $\mathrm{MnCeO}_{\mathrm{x}}$ catalyst in ethanol oxidation. Catal. Commun. 12 (14), 1361-1365.

Li, J.H., Wang, R.H., Hao, J.M., 2010. Role of lattice oxygen and lewis acid on ethanol oxidation over OMS-2 catalyst. J. Phys. Chem. C 114 (23), 10544-10550.
Liang, S., Teng, F., Bulgan, G., Zong, R., Zhu, Y., 2008. Effect of phase structure of $\mathrm{MnO}_{2}$ nanorod catalyst on the activity for CO oxidation. J. Phys. Chem. C 112 (14), 5307-5315.

Liu, J., Makwana, V., Cai, J., Suib, S.L., Aindow, M., 2003. Effects of alkali metal and ammonium cation templates on nanofibrouscryptomelane-type manganese oxide octahedral molecular sieves (OMS-2). J. Phys. Chem. B 107 (35), 9185-9194.

Luo, J., Zhang, Q., Huang, A., Suib, S.L., 2000. Total oxidation of volatile organic compounds with hydrophobic cryptomelane-type octahedral molecular sieves. Microporous Mesoporous Mater. 35-36, 209-217.

Makwana, V.D., Son, Y.C., Howell, A.R., Suib, S.L., 2002. The role of lattice Oxygen in selective benzyl alcohol oxidation using OMS-2 catalyst: a kinetic and isotope-labeling study. J. Catal. 210 (1), 46-52.

Malinger, K.A., Ding, Y.S., Sithambaram, S., Espinal, L., Gomez, S., Suib, S.L., 2006. Microwave frequency effects on synthesis of cryptomelane-type manganese oxide and catalytic activity of cryptomelane precursor. J. Catal. 239 (2), 290-298.

Mitsui, T., Tsutsui, K., Matsui, T., Kikuchi, R., Eguchi, K., 2008. Support effect on complete oxidation of volatile organic compounds over Ru catalysts. Appl. Catal. B Environ. 81 (1-2), 56-63.

Poulopoulos, S.G., Samaras, D.P., Philippopoulos, C.J., 2001. Regulated and unregulated emissions from an internalcombustion engine operating on ethanol-containingfuels. Atmos. Environ. 35 (26), 4399-4406.

Rajesh, H., Ozkan, U.S., 1993. Complete oxidation of ethanol, acetaldehydeand ethanol/methanol mixtures over copper oxide and copper-chromium oxide catalysts. Ind. Eng. Chem. Res. 32 (8), 1622-1630.

Suib, S.L., 2008. Porous manganese oxide octahedral molecular sieves and octahedral layered materials. Acc. Chem. Res. 41 (4), $479-487$.

Tang, X.F., Li, Y.G., Huang, X.M., Xu, Y.D., Zhu, H.Q., Wang, J.G., et al., 2006. $\mathrm{MnO}_{x}-\mathrm{CeO}_{2}$ mixed oxide catalysts for complete oxidation of formaldehyde: effect of preparation method and calcination temperature. Appl. Catal. B Environ. 62 (3-4), 265-273.

Tang, X.L., Zhang, B.C., Li, Y., Xu, Y.D., Xin, Q., Shen, W.J., 2005. The role of $\mathrm{Sn}$ in $\mathrm{Pt}-\mathrm{Sn} / \mathrm{CeO}_{2}$ catalysts for the complete oxidation of ethanol. J. Mol. Catal. A Chem. 235 (1-2), 122-129.

Trawczyñski, J., Bielak, B., Miœta, W., 2005. Oxidation of ethanol over supported manganese catalysts-effect of the carrier. Appl. Catal. B Environ. 55 (4), 277-285.

Wang, F., Dai, H.X., Deng, J.G., Bai, G.M., Ji, K.M., Liu, Y.X., 2012. Manganese oxides with rod-, wire-, tube-, and flower-like morphologies: highly effective catalysts for the removal of toluene. Environ. Sci. Technol. 46 (7), 4034-4041.

Wang, R.H., Li, J.H., 2010. Effects of precursor and sulfation on OMS-2 catalyst for oxidation of ethanol and acetaldehyde at low temperatures. Environ. Sci. Technol. 44 (11), 4282-4287.

Wang, X.J., Wang, H.Y., Liu, Y.C., Liu, F.D., Yu, Y.B., He, H., 2011. A direct sulfation method for introducing the transition metal cation $\mathrm{Co}^{2+}$ into $\mathrm{ZrO}_{2}$ with little change in the Brønsted acid sites. J. Catal. 279 (2), 301-309.

Ye, Q., Gao, Q., Zhang, X.R., Xu, B.Q., 2006. Cataluminescence and catalytic reactions of ethanol oxidation over nanosized $\mathrm{Ce}_{1-\mathrm{x}} \mathrm{Zr}_{x} \mathrm{O}_{2}(0 \leq \mathrm{x} \leq 1)$ catalysts. Catal. Commun. 7 (8), 589-592.

Yuan, J., Li, W., Gomez, S., Suib, S.L., 2005. Shape-controlled synthesis of manganese oxide octahedral molecular sieve three-Dimensional nanostructures. J. Am. Chem. Soc. 127 (41), 14184-14185. 